\title{
Adjacent-segment disease in 511 cases of posterolateral instrumented lumbar arthrodesis: floating fusion versus distal construct including the sacrum
}

\author{
Clinical article
}

\author{
Mohamad Bydon, M.D., ${ }^{1,2}$ Risheng Xu, A.M., ${ }^{1-3}$ David Santiago-Dieppa, B.A., ${ }^{1,2}$ \\ Mohamed Macki, B.S., ${ }^{1,2}$ Daniel M. Sciubba, M.D., ${ }^{1,2}$ Jean-Paul Wolinsky, M.D., ${ }^{1,2}$ \\ Ali Bydon, M.D., 1,2 Ziya L. Gokaslan, M.D., ${ }^{1,2}$ and Timothy F. Witham, M.D.1,2 \\ ${ }^{1}$ Department of Neurosurgery; ${ }^{2}$ Spinal Column Biomechanics and Surgical Outcomes Laboratory; and \\ ${ }^{3}$ Medical Scientist Training Program, Johns Hopkins University School of Medicine, Baltimore, Maryland
}

\begin{abstract}
Object. The aim of this study was to study the long-term outcomes of patients undergoing instrumented posterior fusion of the lumbar spine.

Methods. The authors present 511 patients who underwent instrumented arthrodesis for lumbar degenerative disease over a 23 -year period at a single institution. Patients underwent follow-up for an average of $39.73 \pm 46.52$ months $( \pm \mathrm{SD})$ after the index lumbar arthrodesis procedure.

Results. The average patient age was $59.45 \pm 13.48$ years. Of the 511 patients, $502(98.24 \%)$ presented with back pain, $379(74.17 \%)$ with radiculopathy, $76(14.87 \%)$ with motor weakness, and $32(6.26 \%)$ with preoperative bowel/bladder dysfunction. An average of $2.04 \pm 1.03$ spinal levels were fused. Postoperatively, patients experienced a significant improvement in back pain $(\mathrm{p}<0.0001)$ and radiculopathy $(\mathrm{p}<0.0001)$. Patients with fusions excluding the sacrum (floating fusions) were statistically more likely to develop adjacent-segment disease (ASD) than those with fusion constructs ending at $\mathrm{S}-1$ distally $(\mathrm{p}=0.030)$ but were less likely to develop postoperative radiculopathy $(p=0.030)$. In the floating fusion cohort, $31(12.11 \%)$ of 256 patients had cephalad ASD, whereas $39(15.29 \%)$ of 255 patients in the lumbosacral cohort had cephalad ASD development; this was not statistically different $(\mathrm{p}=0.295)$. This suggests that caudad ASD development in the floating fusion cohort is due to the added risk of an unfused L5$\mathrm{S} 1$ vertebral level. Because of the elevated risk of symptomatic radiculopathy but lower risk of ASD, patients in the lumbosacral fusion cohort had a reoperation rate similar to those undergoing floating fusions $(p=0.769)$.

Conclusions. In this paper, the authors present one of the largest cohorts in the Western literature of patients undergoing instrumented fusion for degenerative lumbar spine disease. Patients who had floating lumbar fusions were statistically more likely to develop ASD over time than those who had lumbosacral fusions incorporating the S-1 spinal segment, but were less likely to experience postoperative radicular symptoms. Additional prospective studies may more clearly delineate the long-term risks of instrumented posterolateral fusions of the lumbar spine.
\end{abstract} (http://thejns.org/doi/abs/10.3171/2013.12.SPINE13789)

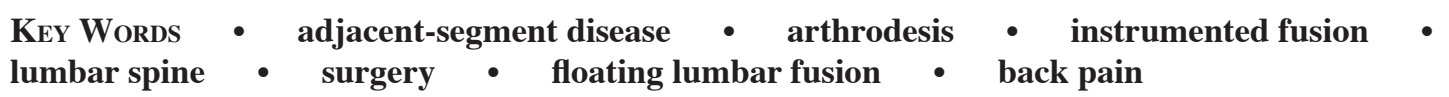

$\mathrm{P}$ OSTERIOR lumbar fusion is a common surgical procedure performed for a number of clinical indications in the lumbar spine, including degenerative conditions such as spondylolisthesis, ${ }^{1,5,6,10,12,15}$ scoliosis, ${ }^{8,9,14,20,24,25}$ and degenerative disc disease,,$^{2-4,18,25,26,35,40,41}$ as well as others such as tumor, infection, ${ }^{46}$ and trauma. ${ }^{31,44,45,47,48}$ As the number of patients who have received lumbar fusions over the past 10-20 years has increased in number, new clinical entities now face the spine surgeon, including the relative contribution of L5-S1 fusion toward long-term outcomes. $7,23,27,30,32,38,39,42,43$

Abbreviations used in this paper: ASD = adjacent-segment disease; $\mathrm{BMP}=$ bone morphogenetic protein.
The L5-S1 spinal segment is a transitional junction between the mobile lumbar spine and the fused sacral promontory. Biomechanically, it represents an area of increased stress, commensurate with the fact that it is a common site for degenerative spondylolisthesis and is one of the most common sites for symptomatic degenerative disc disease development. As instrumented fusion itself creates a discontinuity in the number of mobile vertebral segments in the lumbar spine, its role in affecting L5-S1 biomechanics remains unclear. ${ }^{13,22,28,29,34}$ Thus, although some studies demonstrate increased adjacent-segment disease (ASD) after floating fusion, others have shown that including L5-S1 in the fusion construct appears to be protective against ASD development. 16,17,21 $^{2}$ 


\section{Adjacent-segment disease after posterolateral lumbar fusion}

To better understand the natural history of degenerative spinal disease progression after instrumented fusion, we present a series of 511 patients who received posterior lumbar instrumented fusion for degenerative etiologies at a single institution in the past 23 years. We summarize the preoperative, perioperative, and long-term postoperative outcomes of these patients. In addition, we compare the likelihood of ASD development as a function of fusion location.

\section{Methods}

Data were obtained for all patients undergoing instrumented lumbar arthrodesis for the treatment of degenerative lumbar disease at our institution over a 23-year period from 1990 to 2013. Arthrodesis procedures performed for oncology, infection, trauma, scoliosis, and rheumatological pathology were excluded. Patients with metabolic bone diseases and those undergoing interbody fusion, circumferential fusion, or thoracolumbar fusion were excluded as well. In conducting the study, we retrospectively reviewed clinical notes, operative narratives, and radiology reports. Given that this is a retrospective study, we invariably lost to follow-up some patients who moved away from the region or sought the services of other surgeons. When possible, we attempted to mitigate this factor through telephone calls to inquire about the patients' functional status and surgical history since our last follow-up.
Demographic information, such as age and sex; comorbidities, such as obesity, smoking, hypertension, diabetes, coronary artery disease, and osteoporosis; and presenting symptoms manifested by the patients, such as low-back pain, radiculopathy, weakness, sensory deficits, bowel and bladder dysfunction, were collected and documented for all patients. Intraoperative and perioperative data, such as the number of levels in the arthrodesis construct, intraoperative blood loss, hospitalization length, iatrogenic durotomies, CSF fistula, deep venous thrombosis, pulmonary embolism, infection, hematoma, wound dehiscence, discharge to rehabilitation facilities, reoperations, and instrumentation failure, were also obtained from the medical record. It should be noted that in this series, bone morphogenetic protein (BMP) was used primarily in an off-label manner. Continuous values were compared using the t-test, while binary outcomes were compared using the chi-square test.

\section{Results}

\section{Patient Population}

Between 1990 and 2013, a total of 511 patients underwent instrumented lumbar arthrodesis for the treatment of degenerative lumbar disease. The average age for this cohort was $59.45 \pm 13.48$ years $( \pm$ SD), and 254 patients $(49.71 \%)$ were male (Table 1). Sixty-six patients (12.92\%) had diabetes, 17 (3.33\%) were osteoporotic, 40

TABLE 1: Preoperative characteristics of all patients undergoing lumbar instrumented fusion for degenerative spinal disease $^{*}$

\begin{tabular}{|c|c|c|c|c|}
\hline \multirow[b]{2}{*}{ Parameter } & \multicolumn{3}{|c|}{ Value† } & \multirow[b]{2}{*}{$p$ Value: } \\
\hline & Total Instrumented & Floating Fusion & Lumbosacral Fusion & \\
\hline no. of cases & 511 & 256 & 255 & \\
\hline mean age in yrs & $59.45 \pm 13.48$ & $61.94 \pm 12.85$ & $56.96 \pm 13.65$ & $<0.001$ \\
\hline male sex & $254(49.71)$ & $115(44.92)$ & $139(54.51)$ & 0.030 \\
\hline \multicolumn{5}{|l|}{ comorbidities } \\
\hline diabetes & $66(12.92)$ & $36(14.06)$ & $30(11.76)$ & 0.439 \\
\hline hyperlipidemia & $68(13.31)$ & $35(13.67)$ & $33(12.94)$ & 0.808 \\
\hline COPD & $4(0.78)$ & $2(0.78)$ & $2(0.78)$ & 0.997 \\
\hline coronary artery disease & $62(12.13)$ & $40(15.63)$ & $22(8.63)$ & 0.015 \\
\hline osteoporosis & $17(3.33)$ & $9(3.52)$ & $8(3.14)$ & 0.812 \\
\hline obesity & $40(7.83)$ & $17(6.64)$ & $23(9.02)$ & 0.317 \\
\hline actively smoking & $81(15.85)$ & $41(16.02)$ & $40(15.69)$ & 0.919 \\
\hline hypertension & $179(35.03)$ & $89(34.77)$ & $90(35.29)$ & 0.605 \\
\hline depression & $47(9.20)$ & $21(8.20)$ & $26(10.20)$ & 0.436 \\
\hline \multicolumn{5}{|l|}{ presenting symptoms } \\
\hline back pain & $502(98.24)$ & $249(97.27)$ & $253(99.22)$ & 0.094 \\
\hline radiculopathy & $379(74.17)$ & $186(72.66)$ & $193(75.69)$ & 0.434 \\
\hline motor weakness & $76(14.87)$ & $44(17.19)$ & $32(12.55)$ & 0.141 \\
\hline sensory deficits & 75 (14.68) & $37(14.45)$ & $38(14.90)$ & 0.886 \\
\hline bowel/bladder dysfunction & $32(6.26)$ & $16(6.25)$ & $16(6.27)$ & 0.991 \\
\hline
\end{tabular}

* $\mathrm{COPD}=$ chronic obstructive pulmonary disease.

$\dagger$ Values are the number of patients (\%) unless indicated otherwise. The mean value is presented as \pm SD.

$\ddagger$ Values in boldface are statistically significant. 
$(7.83 \%)$ were morbidly obese, and $81(15.85 \%)$ were active smokers at the time of surgery. A total of 502 patients (98.24\%) presented with back pain and 379 patients (74.17\%) presented with radiculopathy. Preoperative radiculopathy occurred primarily at the L-4, L-5, and/or S-1 levels. Seventy-six patients (14.87\%) presented with motor weakness, 75 patients $(14.68 \%)$ had sensory deficits, and 32 patients $(6.26 \%)$ had preoperative bowel/ bladder dysfunction.

\section{Intraoperative Characteristics}

An average of $2.04 \pm 1.03$ spinal levels were fused in each patient (Table 2). Bone morphogenetic protein was used in 246 patients $(48.14 \%)$. Autograft was used in 400 patients (78.28\%), while autograft with supplemental allograft was used in 282 patients $(55.19 \%)$. The median blood loss was $650 \mathrm{ml}$ (interquartile range 400-1000 ml). The majority of patients $(450$ [88.06\%]) underwent concomitant laminectomy as part of their procedure, but only 170 patients $(33.27 \%)$ also had discectomy. Twenty-seven patients (5.28\%) had an intraoperative durotomy during the surgery.

\section{Perioperative Characteristics}

Perioperatively, the average length of stay was 6.22 \pm 4.60 days (Table 3 ). Thirteen patients (2.54\%) experienced a postoperative CSF leak. Eleven patients (2.15\%) developed a wound infection that required operative intervention. Four patients $(0.78 \%)$ experienced deep venous thrombosis, and $5(0.98 \%)$ experienced pulmonary embolism. Fifty-one patients (9.98\%) were discharged to rehabilitation.

\section{Postoperative Outcomes}

The average follow-up was $39.73 \pm 46.52$ months. During this period, 212 patients $(41.49 \%)$ experienced continued or recurrent back pain (Table 4), and 148 patients $(28.96 \%)$ experienced continued or recurrent radiculopathy. Forty-one (8.02\%) and 31 (6.11\%) patients had recurrent or continued motor or sensory deficits, respectively. Sixteen patients (3.13\%) had continued bowel/ bladder dysfunction. The cumulative rate of ASD development over time was $15.66 \%$ (80 patients). Adjacentsegment disease was defined as radiographic evidence of degeneration at the adjacent level with clinical symptoms necessitating revision surgery. Following univariate logistical regression analysis, social and medical variables (including smoking, osteoporosis, and depression) did not statistically affect the likelihood of ASD ( $p=0.440, p$ $=0.369$, and $p=0.490$, respectively). The overall pseudarthrosis rate was $10.76 \%$ (55 patients). In total, the rate of reoperation due to nonimprovement or worsening of symptoms was $22.50 \%$ (115 patients).

\section{Floating Versus Lumbosacral Fusions}

Among the 511 patients undergoing instrumented lumbar fusion, 256 patients $(50.10 \%)$ received floating fusions, defined as those involving spinal levels L-1 through L-5. In contrast, 255 patients (49.90\%) received a lumbosacral fusion that included the sacrum distally (Table 5). Regarding preoperative prognostic factors, the floating fusion cohort was statistically older $(p<0.001)$ and included a greater number of patients with coronary artery disease $(\mathrm{p}=0.015)$, while the lumbosacral fusion cohort had a statistically higher male prevalence $(\mathrm{p}=0.030)$ (Table 1). There was no statistical difference in the number of patients who received BMP, autograft, or allograft between either of these cohorts (Table 2). Although the floating fusion cohort was statistically more likely to undergo laminectomy $(\mathrm{p}=0.020)$ and discectomy $(\mathrm{p}=$ 0.016 ), the lumbosacral fusion cohort had a statistically larger number of spinal levels fused $(\mathrm{p}<0.001)$. While 49 patients $(19.14 \%)$ in the floating fusion cohort developed ASD requiring reoperation, only 31 patients $(12.16 \%)$ in the lumbosacral fusion cohort developed symptomatic $\operatorname{ASD}(p=0.030)$. Despite having higher rates of ASD development, patients who underwent floating fusion had a lower incidence of postoperative radicular symptoms than those undergoing lumbosacral fusion ( $\mathrm{p}=0.030$ ), as

TABLE 2: Intraoperative characteristics of patients undergoing instrumented arthrodesis due to degenerative spinal disease* $^{*}$

\begin{tabular}{|c|c|c|c|c|}
\hline \multirow[b]{2}{*}{ Parameter } & \multicolumn{3}{|c|}{ Value† } & \multirow[b]{2}{*}{$p$ Valuef } \\
\hline & Total Instrumented & Floating Fusion & Lumbosacral Fusion & \\
\hline no. of patients & 511 & 256 & 255 & \\
\hline mean no. of levels fused \pm SD & $2.04 \pm 1.03$ & $1.64 \pm 0.82$ & $2.44 \pm 1.06$ & $<0.001$ \\
\hline BMP & $246(48.14)$ & $117(45.70)$ & $129(50.59)$ & 0.269 \\
\hline autograft & $400(78.28)$ & $197(76.95)$ & 203 (79.61) & 0.467 \\
\hline allograft & $282(55.19)$ & $135(52.73)$ & $147(57.65)$ & 0.264 \\
\hline median blood loss in ml (IQR) & $650(400-1000)$ & $600(362.5-975)$ & $700(500-1000)$ & \\
\hline incidental durotomy & $27(5.28)$ & $8(3.13)$ & $19(7.45)$ & 0.029 \\
\hline laminectomy & $450(88.06)$ & 234 (91.41) & $216(84.71)$ & 0.020 \\
\hline discectomy & $170(33.27)$ & $98(38.28)$ & $72(28.24)$ & 0.016 \\
\hline
\end{tabular}


Adjacent-segment disease after posterolateral lumbar fusion

TABLE 3: Perioperative characteristics of patients undergoing instrumented fusion for lumbar degenerative spinal disease* $^{*}$

\begin{tabular}{|c|c|c|c|c|}
\hline \multirow[b]{2}{*}{ Parameter } & \multicolumn{3}{|c|}{ Value† } & \multirow[b]{2}{*}{ p Valuef } \\
\hline & Total Instrumented & Floating Fusion & Lumbosacral Fusion & \\
\hline no. of patients & 511 & 256 & 255 & \\
\hline mean length of stay in days $\pm S D$ & $6.22 \pm 4.60$ & $5.95 \pm 4.67$ & $6.51 \pm 4.53$ & 0.197 \\
\hline CSF leak & $13(2.54)$ & $4(1.56)$ & $9(3.53)$ & 0.158 \\
\hline DVT & $4(0.78)$ & $3(1.17)$ & $1(0.39)$ & 0.317 \\
\hline PE & $5(0.98)$ & $4(1.56)$ & $1(0.39)$ & 0.179 \\
\hline wound infection & $11(2.15)$ & $6(2.34)$ & $5(1.96)$ & 0.766 \\
\hline pneumonia & $4(0.78)$ & $2(0.78)$ & $2(0.78)$ & 0.997 \\
\hline hematoma & $3(0.59)$ & $1(0.39)$ & $2(0.78)$ & 0.560 \\
\hline wound dehiscence & $5(0.98)$ & $0(0.00)$ & $5(1.96)$ & 0.024 \\
\hline myocardial infarction & $3(0.59)$ & $2(0.78)$ & $1(0.39)$ & 0.565 \\
\hline death & $1(0.20)$ & $1(0.39)$ & $0(0.00)$ & 0.318 \\
\hline paraplegia & $1(0.20)$ & $1(0.39)$ & $0(0.00)$ & 0.318 \\
\hline discharge to rehab & $51(9.98)$ & 30 (11.72) & $21(8.24)$ & 0.189 \\
\hline
\end{tabular}

* DVT = deep venous thrombosis; PE = pulmonary embolism; rehab = rehabilitation.

$\dagger$ Values are the number of patients (\%) unless noted otherwise.

$\ddagger$ The value in boldface is statistically significant.

well as a lower incidence of pseudarthrosis $(\mathrm{p}=0.113)$, although the latter did not reach statistical significance.

\section{Discussion}

Through the emergence of newer spinal instrumentation techniques and improved imaging modalities, the prevalence of lumbar arthrodesis has continued to increase in the past few decades. ${ }^{19,21,34}$ With the rising numbers of patients undergoing instrumented lumbar fusion, the spinal surgeon must be able to recognize and effectively treat long-term postoperative sequelae such as ASD. Although earlier literature considers ASD a rare entity, more recent case series involving larger patient populations and longer follow-up times reveal that ASD can routinely occur in more than $20 \%$ of the population over a 10 -year span. $7,14,30,33,37$

TABLE 4: Postoperative characteristics of patients undergoing instrumented lumbar fusion for degenerative spinal disease

\begin{tabular}{lc}
\hline \multicolumn{1}{c}{ Parameter } & Instrumentation* $^{*}$ \\
\hline no. of cases & 511 \\
mean total follow-up time in mos \pm SD & $39.73 \pm 46.52$ \\
back pain & $212(41.49)$ \\
radiculopathy & $148(28.96)$ \\
motor symptoms & $41(8.02)$ \\
sensory symptoms & $31(6.11)$ \\
bowel/bladder dysfunction & $16(3.13)$ \\
total reop rate & $115(22.50)$ \\
reop for ASD & $80(15.66)$ \\
\hline
\end{tabular}

* Values are presented as the number of patients (\%) unless noted otherwise.
There is considerable controversy over the pathophysiology of ASD. ${ }^{27}$ Biomechanical studies have supported the increased prevalence of degenerative disease adjacent to the site of bony fusion. Lee and Langrana showed that there is heightened stress at the facet joints of L3-4 and L4-5 after lumbosacral arthrodesis. ${ }^{29}$ Axelsson et al. assessed adjacent segments with the use of radiographic analysis and found hypermobility in the juxtafused segment. ${ }^{4}$ The findings of these studies suggest that instrumented fusion can produce adverse consequences on the integrity of natural biomechanical forces. Commensurate with these findings, we found a significant portion of patients-more than $15 \%$-who developed ASD over a mean time of approximately 40 months. Of note, in this paper, we defined ASD as radiographic disease

TABLE 5: Comparison of intraoperative and postoperative variables of patients undergoing floating versus lumbosacral fusion

\begin{tabular}{lccc}
\hline \multirow{2}{*}{\multicolumn{1}{c}{ Parameter }} & \multicolumn{2}{c}{ No. of Patients (\%) } & \\
\cline { 2 - 3 } & $\begin{array}{c}\text { Floating } \\
\text { Fusion }\end{array}$ & $\begin{array}{c}\text { Lumbosacral } \\
\text { Fusion }\end{array}$ & p Value* \\
\hline no. of cases & 256 & 255 & \\
reop for ASD & $49(19.14)$ & $31(12.16)$ & 0.030 \\
postop back pain & $109(42.58)$ & $103(40.39)$ & 0.616 \\
postop radiculopathy & $63(24.60)$ & $85(33.33)$ & 0.030 \\
postop motor symptoms & $20(7.81)$ & $21(8.24)$ & 0.860 \\
postop sensory symptoms & $17(6.72)$ & $14(5.51)$ & 0.570 \\
pseudarthrosis & $22(8.59)$ & $33(12.94)$ & 0.113 \\
total reop rate & $59(23.05)$ & $56(21.96)$ & 0.769 \\
\hline
\end{tabular}

*Values in boldface are statistically significant. 
M. Bydon et al.

with appropriate clinical symptoms requiring reoperation. This definition may underestimate the incidence of symptomatic ASD as some patients elect not to undergo surgery.

In the lumbar spine, some have hypothesized that floating fusions may give rise to higher incidences of $\mathrm{ASD}$, due to the relative instability of the rostral lumbar spine relative to the caudal lumbosacral spine. In an in vitro biomechanical model, Quinnell and Stockdale demonstrated that lumbar floating fusion causes disproportionate transfer of forces caudad to the fusion construct, whereas discs cephalad to the instrumentation were less likely to be affected. ${ }^{36}$ Thus, Disch et al. showed that of 102 patients who received lumbar fusions, $20 \%$ of patients who received lumbosacral fusions developed ASD, whereas $46 \%$ of those who received floating lumbar fusions developed ASD. ${ }^{11}$ This outcome was clinically significant, as Oswestry Disability Index scores were significantly higher for those with ASD than those without ASD.

Our findings are consistent with this observation, as 49 patients (19.14\%) in the floating fusion cohort developed ASD requiring reoperation, whereas only 31 patients $(12.16 \%)$ in the lumbosacral fusion cohort developed symptomatic ASD ( $\mathrm{p}=0.030)$. Thus, patients receiving posterior instrumented fusion not including the L5-S1 level may be at heightened risk for ASD development. An alternative explanation for this observation may be the fact that fusion of the L5-S1 spinal segment eliminates the possibility of ASD development caudally, as the sacral spine is fused developmentally. Indeed, a closer examination of our patients revealed that $100 \%$ of the 31 patients who developed ASD in the L5-S1 fusion cohort had cephalad ASD development. In contrast, 10 (20.4\%) of 49 patients who developed ASD in the floating fusion cohort had caudad ASD development (Fig. 1).

We wondered whether the rate of caudad ASD development influenced the rate of cephalad ASD development in patients with floating fusions. Thus, we eliminated those patients who developed caudad ASD and only compared the rates of cephalad ASD. In the floating fusion cohort, 31 (12.11\%) of 256 patients had cephalad ASD, whereas 39 (15.29\%) of 255 patients in the lumbosacral cohort had cephalad ASD development. This was not statistically different $(p=0.295)$. These data suggest that caudad ASD development in the floating fusion cohort is due to the added risk of an unfused L5-S1 vertebral level. That is, because the rostral incidence did not statistically differ between the two cohorts, caudal ASD in the floating cohort likely accounts for the increased incidence of ASD.

Because we included patients receiving both single- and multilevel fusions in our analysis, we wanted to examine the rates of ASD development as a function of the number of levels fused. Among patients undergoing single-level fusions, $20 \%$ developed ASD, whereas $13.0 \%$ of patients undergoing multilevel fusions $(\geq 2$ levels) developed ASD. This trended toward but did not reach statistical significance $(\mathrm{p}=0.081)$, suggesting that the rates of ASD development in the lumbar spine may be related to the number of fused vertebral segments.

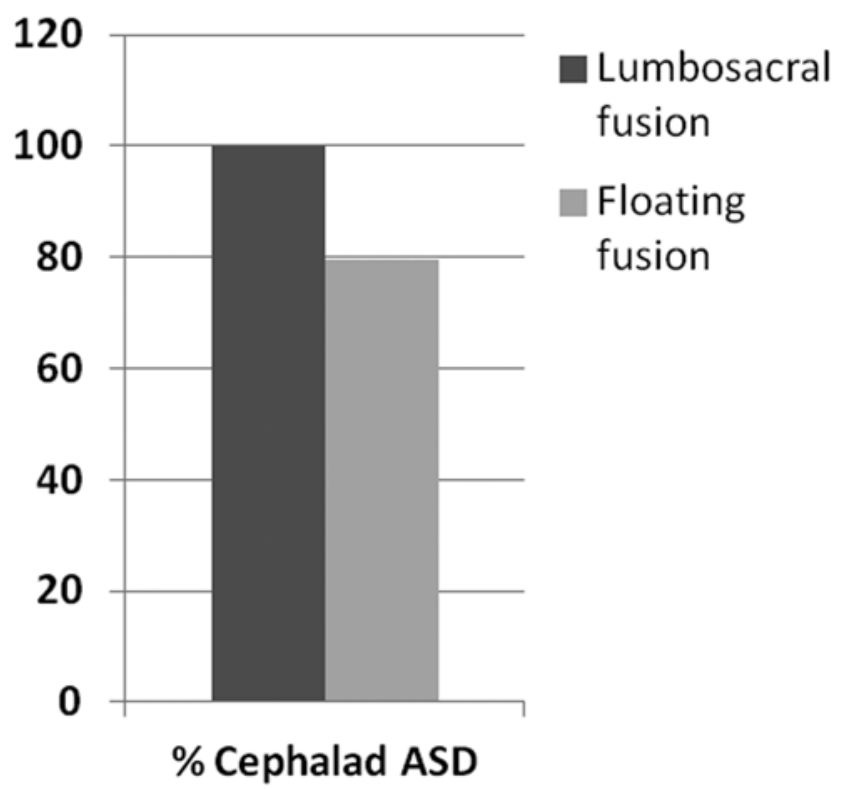

FIG. 1. Comparison of percentage cephalad ASD development as a function of lumbosacral versus floating fusion.

Of note, among patients with cephalad ASD after multilevel fusions, the L2-3 level degenerated in $97.3 \%$ of cases. Similarly, among patients with cephalad ASD after single-level fusions, the L3-4 level degenerated in 77.4\% of cases. While the specified levels may have an intrinsically higher rate of degeneration, the increased rate of cephalad ASD at L2-3 after multilevel fusions and L3-4 after single-level fusions is likely due to the higher prevalence of first-time operations at the L3-5 and L4-5 levels, respectively.

Interestingly, although lumbosacral fusions seem to be associated with lower incidence of ASD development, patients undergoing floating fusions nevertheless experienced better outcomes in terms of radiculopathy $(\mathrm{p}=$ 0.030 ). This was true even though preoperatively there was no statistical difference between the incidence of radiculopathy in the floating versus lumbosacral fusion cohorts $(p=0.434)$. In fact, following a logistical regression of the lumbosacral fusion cohort, postoperative radiculopathy and pseudarthrosis were statistically correlated ( $\mathrm{p}<0.001)$. Thus, although patients receiving noninterbody lumbosacral fusions are less disposed to ASD, they are at heightened risk of postoperative radiculopathy and pseudarthrosis. Because of this, our total reoperation rate was statistically the same $(p=0.769)$.

\section{Conclusions}

In this paper, we present one of the largest cohorts of patients undergoing instrumented fusion for lumbar spinal disease of degenerative etiology. Our results demonstrate that patients undergoing instrumented fusion have statistically significant improved back pain $(\mathrm{p}<0.001)$ and radiculopathy $(\mathrm{p}<0.001)$ postoperatively. Patients who had floating lumbar fusions were statistically more likely to develop ASD over time than those who had lumbosacral fusions incorporating the L5-S1 spinal segment. 


\section{Adjacent-segment disease after posterolateral lumbar fusion}

Because the rostral incidence did not statistically differ between the 2 cohorts, caudal ASD in the floating cohort likely accounts for the increased incidence of ASD. Although the heightened risk of ASD increased the reoperation rate in the floating cohort, the increased rate of postoperative radiculopathy contributed to reoperations in the lumbosacral cohort. Thus, the total reoperation rate is statistically the same. Additional prospective studies may more clearly delineate the potential risk of ASD development as a function of fusion location, as well as long-term outcomes of instrumented posterolateral fusion.

\section{Disclosure}

Timothy Witham is the recipient of a research grant from Eli Lilly and Company. Ziya Gokaslan is the recipient of research grants from DePuy Spine, AOSpine North America, Medtronic, the Neurosurgery Research and Education Foundation, Integra LifeSciences, and K2M. He receives fellowship support from AOSpine North America. He holds stock in Spinal Kinetics and US Spine. Ali Bydon is the recipient of a research grant from DePuy Spine. He serves on the clinical advisory board of MedImmune, LLC. Daniel Sciubba is the recipient of a research grant from DePuy Spine. He has consulting relationships with Medtronic, NuVasive, Globus, and DePuy.

Author contributions to the study and manuscript preparation include the following. Conception and design: Witham, M Bydon, $\mathrm{Xu}$. Acquisition of data: M Bydon, Xu, Santiago-Dieppa, Macki. Analysis and interpretation of data: M Bydon, Xu, Santiago-Dieppa, Macki, Wolinsky. Drafting the article: M Bydon, Xu, SantiagoDieppa. Critically revising the article: all authors. Reviewed submitted version of manuscript: all authors. Approved the final version of the manuscript on behalf of all authors: Witham. Statistical analysis: M Bydon, Xu, Santiago-Dieppa, Macki. Administrative/technical/ material support: Witham, M Bydon, Sciubba, Wolinsky, A Bydon, Gokaslan. Study supervision: Witham, A Bydon, Gokaslan.

\section{References}

1. Ahn DK, Park HS, Choi DJ, Kim KS, Yang SJ: Survival and prognostic analysis of adjacent segments after spinal fusion. Clin Orthop Surg 2:140-147, 2010

2. Audat Z, Moutasem O, Yousef K, Mohammad B: Comparison of clinical and radiological results of posterolateral fusion, posterior lumbar interbody fusion and transforaminal lumbar interbody fusion techniques in the treatment of degenerative lumbar spine. Singapore Med J 53:183-187, 2012

3. Auerbach JD, Jones KJ, Milby AH, Anakwenze OA, Balderston RA: Segmental contribution toward total lumbar range of motion in disc replacement and fusions: a comparison of operative and adjacent levels. Spine (Phila Pa 1976) 34:25102517, 2009

4. Axelsson P, Johnsson R, Strömqvist B, Arvidsson M, Herrlin $\mathrm{K}$ : Posterolateral lumbar fusion. Outcome of 71 consecutive operations after 4 (2-7) years. Acta Orthop Scand 65:309314, 1994

5. Boos N, Marchesi D, Zuber K, Aebi M: Treatment of severe spondylolisthesis by reduction and pedicular fixation. A 4-6year follow-up study. Spine (Phila Pa 1976) 18:1655-1661, 1993

6. Cheng L, Nie L, Zhang L: Posterior lumbar interbody fusion versus posterolateral fusion in spondylolisthesis: a prospective controlled study in the Han nationality. Int Orthop 33:1043-1047, 2009

7. Cho KJ, Suk SI, Park SR, Kim JH, Kang SB, Kim HS, et al: Risk factors of sagittal decompensation after long posterior instrumentation and fusion for degenerative lumbar scoliosis. Spine (Phila Pa 1976) 35:1595-1601, 2010
8. Cho KJ, Suk SI, Park SR, Kim JH, Kim SS, Choi WK, et al: Complications in posterior fusion and instrumentation for degenerative lumbar scoliosis. Spine (Phila Pa 1976) 32:22322237, 2007

9. Cho KJ, Suk SI, Park SR, Kim JH, Kim SS, Lee TJ, et al: Short fusion versus long fusion for degenerative lumbar scoliosis. Eur Spine J 17:650-656, 2008

10. Dehoux E, Fourati E, Madi K, Reddy B, Segal P: Posterolateral versus interbody fusion in isthmic spondylolisthesis: functional results in 52 cases with a minimum follow-up of 6 years. Acta Orthop Belg 70:578-582, 2004

11. Disch AC, Schmoelz W, Matziolis G, Schneider SV, Knop C, Putzier M: Higher risk of adjacent segment degeneration after floating fusions: long-term outcome after low lumbar spine fusions. J Spinal Disord Tech 21:79-85, 2008

12. Ekman P, Möller H, Hedlund R: The long-term effect of posterolateral fusion in adult isthmic spondylolisthesis: a randomized controlled study. Spine J 5:36-44, 2005

13. Esses SI, Doherty BJ, Crawford MJ, Dreyzin V: Kinematic evaluation of lumbar fusion techniques. Spine (Phila Pa 1976) 21:676-684, 1996

14. Etebar S, Cahill DW: Risk factors for adjacent-segment failure following lumbar fixation with rigid instrumentation for degenerative instability. J Neurosurg 90 (2 Suppl):163-169, 1999

15. Farrokhi MR, Rahmanian A, Masoudi MS: Posterolateral versus posterior interbody fusion in isthmic spondylolisthesis. J Neurotrauma 29:1567-1573, 2012

16. Ghiselli G, Wang JC, Bhatia NN, Hsu WK, Dawson EG: Adjacent segment degeneration in the lumbar spine. J Bone Joint Surg Am 86-A:1497-1503, 2004

17. Ghiselli G, Wang JC, Hsu WK, Dawson EG: L5-S1 segment survivorship and clinical outcome analysis after L4-L5 isolated fusion. Spine (Phila Pa 1976) 28:1275-1280, 2003

18. Hallett A, Huntley JS, Gibson JN: Foraminal stenosis and single-level degenerative disc disease: a randomized controlled trial comparing decompression with decompression and instrumented fusion. Spine (Phila Pa 1976) 32:1375-1380, 2007

19. Harrop JS, Youssef JA, Maltenfort M, Vorwald P, Jabbour P, Bono CM, et al: Lumbar adjacent segment degeneration and disease after arthrodesis and total disc arthroplasty. Spine (Phila Pa 1976) 33:1701-1707, 2008

20. Heary RF, Karimi RJ: Correction of lumbar coronal plane deformity using unilateral cage placement. Neurosurg Focus 28(3):E10, 2010

21. Hilibrand AS, Robbins M: Adjacent segment degeneration and adjacent segment disease: the consequences of spinal fusion? Spine J 4 (6 Suppl):190S-194S, 2004

22. Hoogendoorn RJ, Helder MN, Wuisman PI, Bank RA, Everts VE, Smit TH: Adjacent segment degeneration: observations in a goat spinal fusion study. Spine (Phila Pa 1976) 33:13371343,2008

23. Kaito T, Hosono N, Fuji T, Makino T, Yonenobu K: Disc space distraction is a potent risk factor for adjacent disc disease after PLIF. Arch Orthop Trauma Surg 131:1499-1507, 2011

24. Katz JN, Lipson SJ, Lew RA, Grobler LJ, Weinstein JN, Brick $\mathrm{GW}$, et al: Lumbar laminectomy alone or with instrumented or noninstrumented arthrodesis in degenerative lumbar spinal stenosis. Patient selection, costs, and surgical outcomes. Spine (Phila Pa 1976) 22:1123-1131, 1997

25. Kumar MN, Baklanov A, Chopin D: Correlation between sagittal plane changes and adjacent segment degeneration following lumbar spine fusion. Eur Spine J 10:314-319, 2001

26. Kuslich SD, Ulstrom CL, Griffith SL, Ahern JW, Dowdle JD: The Bagby and Kuslich method of lumbar interbody fusion. History, techniques, and 2-year follow-up results of a United States prospective, multicenter trial. Spine (Phila Pa 1976) 23:1267-1279, 1998 


\section{Bydon et al.}

27. Lawrence BD, Wang J, Arnold PM, Hermsmeyer J, Norvell DC, Brodke DS: Predicting the risk of adjacent segment pathology after lumbar fusion: a systematic review. Spine (Phila Pa 1976) 37 (22 Suppl):S123-S132, 2012

28. Lee CK: Accelerated degeneration of the segment adjacent to a lumbar fusion. Spine (Phila Pa 1976) 13:375-377, 1988

29. Lee CK, Langrana NA: Lumbosacral spinal fusion. A biomechanical study. Spine (Phila Pa 1976) 9:574-581, 1984

30. Lee CS, Hwang CJ, Lee SW, Ahn YJ, Kim YT, Lee DH, et al: Risk factors for adjacent segment disease after lumbar fusion. Eur Spine J 18:1637-1643, 2009

31. Lee MJ, Dettori JR, Standaert CJ, Ely CG, Chapman JR: Indication for spinal fusion and the risk of adjacent segment pathology: does reason for fusion affect risk? A systematic review. Spine (Phila Pa 1976) 37 (22 Suppl):S40-S51, 2012

32. Norvell DC, Dettori JR, Skelly AC, Riew KD, Chapman JR, Anderson PA: Methodology for the systematic reviews on an adjacent segment pathology. Spine (Phila Pa 1976) 37 (22 Suppl):S10-S17, 2012

33. Okuda S, Iwasaki M, Miyauchi A, Aono H, Morita M, Yamamoto T: Risk factors for adjacent segment degeneration after PLIF. Spine (Phila Pa 1976) 29:1535-1540, 2004

34. Park P, Garton HJ, Gala VC, Hoff JT, McGillicuddy JE: Adjacent segment disease after lumbar or lumbosacral fusion: review of the literature. Spine (Phila Pa 1976) 29:1938-1944, 2004

35. Periasamy K, Shah K, Wheelwright EF: Posterior lumbar interbody fusion using cages, combined with instrumented posterolateral fusion: a study of 75 cases. Acta Orthop Belg 74:240-248, 2008

36. Quinnell RC, Stockdale HR: Some experimental observations of the influence of a single lumbar floating fusion on the remaining lumbar spine. Spine (Phila Pa 1976) 6:263-267, 1981

37. Radcliff K, Curry P, Hilibrand A, Kepler C, Lurie J, Zhao W, et al: Risk for adjacent segment and same segment reoperation after surgery for lumbar stenosis: a subgroup analysis of the Spine Patient Outcomes Research Trial (SPORT). Spine (Phila Pa 1976) 38:531-539, 2012

38. Schaeren S, Broger I, Jeanneret B: Minimum four-year follow-up of spinal stenosis with degenerative spondylolisthesis treated with decompression and dynamic stabilization. Spine (Phila Pa 1976) 33:E636-E642, 2008

39. Sears WR, Sergides IG, Kazemi N, Smith M, White GJ, Osburg B: Incidence and prevalence of surgery at segments adjacent to a previous posterior lumbar arthrodesis. Spine $\mathbf{J}$ 11:11-20, 2011
40. Siemionow KB, Hu X, Lieberman IH: The Fernstrom ball revisited. Eur Spine J 21:443-448, 2012

41. Togawa D, Bauer TW, Brantigan JW, Lowery GL: Bone graft incorporation in radiographically successful human intervertebral body fusion cages. Spine (Phila Pa 1976) 26:27442750,2001

42. Turunen V, Nyyssönen T, Miettinen H, Airaksinen O, Aalto T, Hakumäki J, et al: Lumbar instrumented posterolateral fusion in spondylolisthetic and failed back patients: a long-term follow-up study spanning 11-13 years. Eur Spine J 21:21402148, 2012

43. Untch C, Liu Q, Hart R: Segmental motion adjacent to an instrumented lumbar fusion: the effect of extension of fusion to the sacrum. Spine (Phila Pa 1976) 29:2376-2381, 2004

44. Vialle R, Wolff S, Pauthier F, Coudert X, Laumonier F, LortatJacob A, et al: Traumatic lumbosacral dislocation: four cases and review of literature. Clin Orthop Relat Res (419):91-97, 2004

45. Xu R, Solakoglu C, Kretzer RM, McGirt MJ, Witham TF, Bydon A: Bilateral traumatic dislocation without fracture of the lumbosacral junction: case report and review of the literature. Spine (Phila Pa 1976) 36:E662-E668, 2011

46. Xue HB, Ma YZ, Chen X, Li HW, Cai XJ, Guo LX, et al: [Surgical treatment of spinal tuberculosis in aged.] Zhonghua Wai Ke Za Zhi 45:1233-1236, 2007 (Chinese)

47. Zhang SD, Wang C, Chen H, Wu XT, Mao ZB, Yang HL, et al: [Preliminary experiences in minimally invasive transforaminal lumbar interbody fusion.] Zhonghua Wai Ke Za Zhi 47:112-115, 2009 (Chinese)

48. Zhou TH, Tang X, Xu YQ, Zhu YL: Traumatic spondyloptosis of L4. Spine (Phila Pa 1976) 35:E855-E859, 2010

Manuscript submitted August 22, 2013.

Accepted December 26, 2013.

Please include this information when citing this paper: published online January 31, 2014; DOI: 10.3171/2013.12.SPINE13789.

Address correspondence to: Timothy F. Witham, M.D., Department of Neurosurgery, The Johns Hopkins Hospital, Meyer 7-109, 600 N. Wolfe St., Baltimore, MD 21287. email: twitham2@jhmi. edu. 